\title{
Fit the new features of the new class of students and teaching instructional text design direction
}

\author{
Yan Han \\ Jiangsu province xuzhou technician institute, Xuzhou, Jiangsu 221151, China \\ 1030638329@qq.com
}

Key words: new case,designed to teach,new class teaching

\begin{abstract}
The teaching and case preparation for teaching should teach the characteristics of the object. This paper analyzes the current basis "after 00 " The new features of the new class groups of students on language teaching in vocational education, for example, from a focus point, difficult point, growing point, the point of negligence, excitement five aspects, shall determine instructional design and science teaching fit direction.
\end{abstract}

\section{Introduction}

The New Students refers to 2000-2009 newest generation born "after 00" Chinese citizens, they are basically born in China's reform and opening, have remarkable results after 70 only child. Since September 2015, they poured into the vocational education and gradually become the main secondary vocational education. These students living in materialistic age, grew up in the parents Zhongxingpengyue favor, although material well, but the lack of pleasure, endurance is poor, can not suffer, they do not love reading, obsessed with the network, due to pre-onerous burden and "defeated" frustration, weariness and even interest in learning is not strong, the traditional "giving and receiving" approach has failed.

Contemporary cognitive psychologists Ausubel said: "If I had to revert to a principle of educational psychology, I would say that the most important factors affecting the learning of students already know what we should be according to the student the existing state of knowledge to teaching. "Therefore, the case must be written for teaching students to respect their knowledge and experience real, and thinking development reality, according to their level of development and ability differences in personality development, appropriate teaching content organization, select the appropriate teaching methods, to arrange for appropriate teaching activities, in order to stimulate self-learning potential. In this paper, language teaching, for example, closely linked to the new features of the new class groups of students will be prepared in accordance with the teaching case can be summarized as five points, but also the direction of the top five teaching teachers teaching the design process considered.

\section{First, the focus - fit student perspective}

Teaching case concerns the preparation of the new generation of problem students from starting after 00. Educators famous Zankov said: "when it comes to teaching students in the field of emotions and will, reach the spiritual needs of the students, this teaching method can play a highly effective role." Therefore, the teaching in the preparation of the case must be understand the students' current level of knowledge, ability level, from student learning needs, designing and writing and student life practice, fit the emotional experience, and teaching content to adapt 
teaching case. For example, teaching Cai "became the president of Peking University speech," The article is a classical, a bit depth of context, from the old era, teachers will have to explain the translation preaching is suspected, the student is bound to feel dreary things, reach past serve the present effect. So I default on the basis of the three group discussions do induction, expand freedom of learning in the classroom, distributed learning tasks, so every team can give students sufficient time to read and room for discussion, let students talk about the three points in the moment social significance: the first point, "clung to the purpose," the student sees today's society impetuous, reading useless and money talks' bad is rampant; the second point "moral temper", students talked about the current quality of education, moral education a mere formality, since the lack of management schools, many students just for the sake of pleasure, faith landslide, moral decay, neglect their studies, ruin the future; the third point, "Dear teachers and friends," the students after 00 mostly one-child, as the only child at home, there are selfish, overweening character. The eyes of parents not at home, not in the eyes of the school teachers, the teacher glaring criticisms, students cold numbness, arm's length. Students' own analysis, it is the teachers didactic content, but through the mouth of the students say, even in well-meaning teachers. This will not only through teaching case the effective completion of learning tasks, but also to better meet students' psychological needs and emotional experience, training students imagination and language skills.

\section{Second, the difficult point - Collaboration Discussion Problems}

In the preparation of teachers teaching the case, we must fully research students in learning exist doubts and confusion. Excellent teaching case must be both cognitive basis of respect for the students, concerned about the students' doubts difficulties, and focusing on the teaching objectives and teaching content heavy and difficult to design. Only teaching case design concerns the students feel a certain difficulty in question, to be able to stimulate students' positive thinking to break through this problem, in-depth study of learning, discussion of the text. For example Maupassant novel "necklace", this article is in Chinese Textbooks for many years retained a famous writer, short story represented. Text can design a lot of problems, such as the hero character Mathilde analysis, at the end of the short story climax artistic ideas other problems have students reading comprehension doubts and difficulties. Compared with traditional teaching, I did not design this class of teachers and students a question and answer, no teacher layers questioning, no statement from the students listen to the count, nor punctuate comment after speaking students, but allow students to express their opinions their own questions, discuss issues with their own understanding of a text on the sign languages sublimation refining, in order to complete a student-between, between life and life, and intelligent communication and dialogue between teachers and students thinking beyond textbooks, beyond teaching. I deeply feel that every detail of the text has been excavated out of the students, which is more detailed than the teachers teach, in-depth, comprehensive, in order to give this issue the best place to answer. Therefore, teachers should pay attention to empathy, taking into account the student's level of intelligence and the ability to accept differences of knowledge, taking into account the perspective of students standing in a text'll see what indwelling design teaching students found time to deal with the case in question, only help students explore issues of direction and guidance, to discuss with them thinking, enhance understanding and interpretation of the text together.

\section{Third, the growing point - identify the cut height}

In the case of the preparation of the teaching, the teacher must be based on existing knowledge 
level of the students, the students determine the zone of proximal development, the growing point to find the students' knowledge and develop learning content, design learning activities. Because, on the face of the case teaching groups - students, "they are in the first world of life, the world is a living entity, but also a whole world of education can not be dismembered objects facing life education", teaching the students need existing world and knowledge of the world will be constructed to link up and stand in the teaching case is the bridge and link between the two. So, look for students growing point for the preparation of the case for teaching is particularly important, and out of the growing point, and then a big effort to pay teachers, can only be inefficient or ineffective labor. - As Aldo Leopold "Think like a mountain," a lesson, I heard a wolf howl article from close-up Zhaobi. Bring awareness wrapped OF deep concern - he narrating poetic and profound ecological concerns hybridity wolf howl at the sound of the soul gives a shock. Next, write a note of deer, coyotes, shepherds, hunters this wolf howl sound response. On further pointed out that, after the shallow hopes and fears, as well as deeper, only the mountain can understand the meaning. The author of a profound ecological ethics issues in a very poetic image language expression out of concern and Thinking readers. The text is a clear theme profound, moral goals visible today. I believe that before learning this article, let the students is necessary to re-examine their live land surrounding environment and feel great destruction on the ecological development of the industrial society. Therefore, before the text into the title, instructional design dedicated 20 minutes to listen to the voice of student, students feel the eyes of the ecological community, listening to a sense of crisis hearts of the students. In view of this, into the text, students and authors from the more recent, and reach a consensus thinking, understand Consideration mountain breeze.

\section{Fourth, missing point -enforcing weak points}

Teaching case preparation, there is a problem can not be ignored, is the double base culture on students, especially to help students firmly grasp the basic knowledge learned. In the learning process, we often find that many students will be common word, polyphonic sound words not allowed to read, and even some basic knowledge of literature are handled badly. Works such as "Thunderstorm" was written by Cao $\mathrm{Yu}$, although it is compulsory table of contents, but will always appear on each student papers "Lao She," the answer, and a certain proportion. Analysis found that students confuse the two playwrights, the main source of literary knowledge level is not strong. Another example is "shade" and "shade tree" Two words, students are often written as "shade" and "big shade shelter." Dictionary for which the "yin" One explanation is: where the sun does not shine directly; on the "shade" One explanation is: the shade, under a tree sunless place. Both contain similar meaning. But otherwise stated in the "shade" note in 1985, "Chinese Different Words Forms" provides "shade" EC read yìn, "shade", "avenue" should be "shade", "avenue." Only in some fixed format such as "trees" and the specific terms such as place names, the original reading yīn, means "shade" remains unchanged on the meaning of "shady" character to get used to. Thus, the "shade", "avenue" in the "yin" written word should not be written as "shady", so does not meet specifications. The reason why the student repeatedly wrong, wrong link leads to experience. These two proof reflect weak students the basics. As a mature language teacher in the teaching of the preparation of the case must be aware of the real "Student-centered" teaching is in line with the teaching of students physical and mental development, rather than cater to the tastes of teaching students. Simply fun, regardless of function. Because students must not neglect the basics, we are not interested in even bored, teachers ignored. Because, any culture may be based on the ability to master certain knowledge. Therefore, these basics are neglected students, teachers can use in teaching case "Keqianyuxi", "homework" and part of the design and effective exercises, so students 
can not only cause concern for knowledge, but also to strengthen the students' memory, while improving students' ability to use play a multiplier effect.

\section{Fifth, the excitement - always catching attention}

Classroom teachers and students to the stage performances, guide students are required to participate in performances of modern teaching. Whether the student teaching text content of interest, whether dedicated to invest in, are important factors affecting learning whether the expected results, to achieve the desired objectives. Therefore, teachers in the preparation of teaching case must find and seize the students' interests, the center of interest and excitement, so that students learn in a pleasant learning in excitement, explore, feel the joy of learning and the joy of success. For example, "Zeng Xi Zi Ran Yougong Xihua Shizuo chapter," a text teaching, translation text, the characters try to figure out ideological character is important difficulties in teaching. Vocational school students to consider accepting a certain degree of difficulty of this article, we will break the design of teaching reading, translation, reading this routine, role playing to teach the text, so that students on the ground, feel the four disciples of Confucius and the text conversation experience figure on the scene, and more intuitive than teachers teach and students to read, vivid, so that the role of students standing position, closer to work, close to the people, not only can the rapid appearance of teaching materials, also becomes so difficult to understand classical too lively, straightforward and easy to understand. As the students said, as if the text of the things in our midst, the text characters is our students, the psychological character is our own psychology. For episode distinctive "Lotus Lake", "bowl of soup noodles" and other contents also apply to the teaching method. Also on the theme of teaching content, teachers can prepare 2-3 draw inferences and embellishment of stories interspersed teaching process, to ensure that students throughout the energy is not a free classroom, fatigue, malaise learning time is always fresh examples to refreshing, thereby maintaining attention and focus.

\section{Conclusions}

Teaching is a science, but an art. In the teaching process, teachers should use a unique teaching techniques designed to optimize the classroom results. Five directions of teaching case design is the starting point of teaching, but also a foothold, only targeted to Xueding teaching, in order to achieve the effectiveness of science teaching.

\section{References}

[1] Mo Lei. [M]. education psychology in Guangzhou: Guangdong Higher Education Press. 2005.114 .

[2] Guo Yuanxiang. Life and education returning to the life world of elementary education [M]. Wuhan: Huazhong Normal University press. 2002.116.

[3] Fan Zengmin. Study on the teaching model of guided learning plan [D] of Qufu Normal University master's thesis.2003. 